\title{
A Study of Inventory Control Systems by Jamaican SMEs in Retail and Manufacturing/Distribution Industries
}

\author{
Fashaya Johnson ${ }^{1} \&$ Thanasak Ruankaew ${ }^{1}$ \\ ${ }^{1}$ School of Management, University of Liverpool, UK \\ Correspondence: Thanasak Ruankaew, School of Management, University of Liverpool, UK. E-mail: \\ thanasak.ruankaew@online.liverpool.ac.uk
}

Received: June 2, 2017

Accepted: July 5, 2017

Online Published: July 18, 2017

doi:10.5539/ijbm.v12n8p1

URL: https://doi.org/10.5539/ijbm.v12n8p1

\begin{abstract}
It is widely accepted that firms can achieve effective inventory management with the right strategies. This study analyzed the inventory control strategies of small to medium-sized enterprises (SMEs) in Jamaica. The objectives of the study were to identify whether these companies used the "best practices" in inventory control, the effects of their strategies on business performance, and the factors that affected the development of their strategies. The study employed a methods triangulation approach that included case studies, interviews, questionnaires, and observation with a focus on twelve inventory-intensive SMEs in retail and manufacturing/distribution industries. The SMEs were found to use common inventory control strategies such as stock counts, Enterprise Resource Planning (ERP) systems, forecasting, and inventory classification.

The findings of this study support institutional theory and isomorphism because it was discovered that due to external influences, firms studied within the same industry adopted similar strategies, and even in different industries, the 'best practices' in inventory control were the same. The drivers of this isomorphic organizational behavior were found to be costs, government regulations, and imitation of successful strategies in other companies. The SMEs surveyed were classified as semi-automated due to limited automation and confirmed success in their inventory management. The study validates the existence of institutionalism among SMEs in the retail as well as manufacturing/distribution industries in Jamaica. A broader scope examining larger firms and other industries would further identify isomorphic organizational behavior across the Jamaican business landscape. For future research, an investigation of financial performance and changes and adoption of new inventory control strategies of Jamaican SMEs is recommended to achieve a broad view of inventory management on the financial performance of Jamaican SMEs.
\end{abstract}

Key Words: SMEs, inventory management, inventory control systems, institutional theory

\section{Introduction}

\subsection{Background}

Research into the inventory management practices of Jamaican Small and Medium-sized Enterprises (SMEs) is limited, as few articles have been published on this topic within the Jamaican business context. However, it is expected that the typical challenges of inventory management among firms worldwide are also being faced by Jamaican SMEs. The European Commission's standard of an SME is applied to this study, according to which the characteristics of an SME are as follows: a maximum of 250 employees, an annual of turnover no more than EUR 50 million, or an annual balance sheet not exceeding EUR 43 million (European Union, 2015). For this research, only the number of employees was used to categorize the companies examined, as the authors anticipated reluctance in the disclosure of balance sheet data, which is not essential for this analysis. The scope of the study was limited to inventory-intensive SMEs in retail and manufacturing/distribution industries within the Jamaican economy.

The best-case scenario of an inventory management model assumes implicitly that physical stock is equal to the stock represented in the information system (Khader, Rekik, Botta-Genoulaz, and Campagne, 2014). However, various factors hinder this ideal situation. Flawless inventory records are hard to maintain and inventory records are quite likely to be incorrect (Kang and Gershwin, 2005). Common causes of inaccuracies in inventory records are incorrect product identification, stock loss, and transaction errors (Kang and Gershwin, 2005). There are 
often discrepancies between physical stock and recorded inventory, resulting in inventory inaccuracies that may become a hindrance to performance improvement for many firms (Khader et al., 2014). Coupled with discrepancies, other challenges to inventory management include stock-outs, excess stock, and obsolete inventory. Inventory management is the monitoring and controlling of inflow and outflow of goods. High inventory turnover is critical to SMEs' operations, and is used as a key performance indicator for the effective management of stock. SMEs often find it difficult to adequately manage their inventory and employ various inventory control systems to correct inefficiencies, eliminate inventory waste, and provide accurate inventory data. These strategies vary from those with significant manual interface to those that use automation through information systems.

Inventory management strategies of SMEs have been largely covered in other research, but strategies of inventory control among Jamaica SMEs have not received much attention. The theoretical framework of this research motivates the examination of whether external factors influence the adoption of inventory management strategies within retail and manufacturing/distribution firms in Jamaica. The effectiveness of these strategies was assessed through an analysis of inventory turnover ratio (ITR) within the SMEs. Additionally, the extent to which optimal inventory management is achieved by mirroring those of a similar entity was investigated.

\subsection{Research Aims and Objectives}

The purpose of the research was twofold. Firstly, it was aimed to provide detailed insight into the strategies of inventory control within the Jamaican business economy, while assessing whether institutional theory has shaped the development of these strategies. The second aim was to discover whether similar strategies exist among SMEs within the same industries to validate isomorphism of institutional theory within the Jamaican business landscape.

Institutional theory suggests that the beliefs, values, and practices within an organization are influenced and shaped by external factors. External factors may include regulations, as well as policies or practices of other organizations. According to institutional theory, all organizations are treated the same, adopting the same practices and strategies, but the heterogeneity of organizations is ignored (Meyer and Höllerer, 2014). Institutional theory as it relates to inventory management within Jamaican SMEs was tested. The authors tried to ascertain whether the strategies established were due to the influence of external factors. The objective was to determine whether similarities exist among the strategies used in these SMEs, and to endorse or disprove whether isomorphic organizational behavior is the driving factor behind the implementation of various inventory control systems within SMEs in Jamaica. The research was also intended to determine which could be considered the most suitable and effective inventory control strategies for retail and manufacturing/distribution SMEs, given the Jamaican business landscape.

\subsection{Research Questions}

With a focus on two medium-sized enterprises as case studies and ten other SMEs within the same industry, an assessment was made on similarities or differences between their strategies of inventory control. By measuring their ITR, the research attempted to reveal whether with similar practices, similar performance results were achieved. The research questions below were also tailored to evaluate whether institutional theory and adoption of "best practices" in inventory management are applicable to Jamaican SMEs in relation to inventory management.

- What are the strategies that Jamaican retail and manufacturing/distribution SMEs use for inventory control and what are the factors that influenced their development?

- How effective are the strategies for inventory control based on ITR?

- What percentage of Jamaican retail and manufacturing/distribution SMEs use automated inventory control systems and what are the benefits?

- How do the strategies of inventory control impact on business performance for these SMEs?

- To what extent do the strategies for inventory control differ among SMEs in Jamaica within the same industry?

\subsection{Theoretical Framework}

Institutional theory explains how the influences of the institutional environment, i.e., government agencies, laws, social and economic norms, interest groups, and public opinion, shape an organization's behavior. Institutional theory focuses on the "imitation of organizational structure, practices and policies; in response to state pressure, the expectations of the profession or industry, or the collective norms of the institutional environment" (Oliver, 
1991, p. 147). Meyers and Rowan (1977) argued that it is the institutionalized concepts and social processes that have come to take on "rulelike" status within a society on which organizational structures are built. Within institutional theory, isomorphism is frequently discussed. Kauppi (2013) highlighted two variants to institutional theory - social and economic - both driven by uncertainty and resulting in benchmarking among organizations. Social variant isomorphism, which refers to similarities in processes or structure among organizations, increases as organizations seek legitimacy, while the economic variant describes the mimicking behavior of organization as they seek efficiency (Kauppi, 2013). Faced with the same environmental conditions, whether isomorphism is coercive, mimetic, or normative, it is a compelling process that forces one organization in an industry to be like other organizations (DiMaggio and Powell, 1983). When an organization is faced with pressures from other organizations on which it relies, this is referred to as coercive isomorphism, while pressures of a profession, such as conditions or procedures of work, or sometimes licensing, is considered normative isomorphism (DiMaggio and Powell, 1983). Mimetic isomorphism, which is widely discussed in several studies, is described as an imitation of one organization's structure by another due to the belief that the structure of the mirrored organization is beneficial and successful (DiMaggio and Powell, 1983). Kauppi (2013) categorized coercive, mimetic, and normative as sociological mechanisms of institutional isomorphism and mentioned three economic mechanisms or modes of imitation. Kauppi (2013) described these imitation methods as (1) frequency-based, which is the unconscious imitation of actions previously taken by many organizations, (2) trait-based, which is mimicking organizations with selected traits, and (3) outcome-based, which is the imitation of actions that have appeared to be successful in other organizations. The economic mechanisms put forward by Kauppi (2013) can be classified within DiMaggio and Powell's (1983) mimetic isomorphism, as they reflect the mimicking of one organization by another. Both DiMaggio and Powell (1983) and Kauppi (2013) attributed isomorphism to uncertainty within the business environment. Organizations are often unsure about the efficiency of their structure and practices, and therefore seek to imitate other firms that they perceive as having successful practices and policies (Kauppi, 2013). DiMaggio and Powell (1983, p.151) believed that "when organizational technologies are poorly understood; when goals are ambiguous and there is uncertainty within the environment, organizations model themselves based on other organizations". Imitation of practices and structures due to uncertainty increases benchmarking among organizations.

Institutional theory stresses that survival of an organization is based on conforming to the institutionalized agreements and adherence to external rules and norms (Oliver, 1991). To be accepted and be considered legitimate, as well as to increase their chance of surviving, organizations are driven to integrate the practices and procedures that are institutionalized in a society (Meyer and Rowan, 1977). Conformance occurs when the organization, without question, defines and structures its activities in functional areas such as sales, production, and inventory management, based on institutionalized prefabricated classifications of appropriate structure (Oliver, 1991). Nevertheless, organizations can resist institutional pressures. Oliver (1991) stated that the extent to which organizations conform or resist institutional pressures is based on why the pressure is being exerted, who is exerting the pressure, what the pressures are, how they are being exerted, and where the pressure occurs. In the broader context, organizations conform due to a desire to fit in socially, to achieve legitimacy, and to have access to resources, often at the expense of efficiency within the organization. It is argued that there are both benefits and hindrances for an organization that conforms to the institutional environment. The benefits are an increase in positive evaluation and resources inflow, at the expense of a reduction in efficiency (Zucker, 1987). Meyer and Rowan (1977) supported the notion that conformism to institutionalized rules conflicts with efficiency measures. Internal goals and values, legitimacy of external legitimacy of external control, and the control or power of the organization are factors that determine the influence of institutional pressures on the organization (Zucker, 1987).

Farooquie and Khan (2010) appropriately stated that effective inventory management requires matching costs with the benefits of holding the inventory. Inventory management practices are widely used to achieve high inventory turnovers and to avoid excess stock, inventory discrepancies, stock-out, and other issues associated with inventory management. The models or techniques of inventory management include Economic Order Quantity (EOQ) and Inventory Classification, as well as modern practices such as Lean Procurement, Just-in-Time (JIT), use of Enterprise Resource Planning (ERP) systems, and Materials Requirement Planning (MRP), to name a few. Regardless of the methods used, the objective remains the same: having the right stock to achieve sales and profitability. The first step in managing inventory is classifying items (Lopez, Mendoza, and Masini, 2013). Knowing the inventory and understanding the importance of each item is critical to effective inventory management. The widely used $\mathrm{ABC}$ Classification of inventory reduces the complexity of managing the vastness of a company's inventory and allows the firm to design models and established control practices geared to certain groups of items (Lopez et al, 2013). Forecasting, stock counts, and inventory rationalization are 
considered "best practices" in inventory management. Organizations can combine various practices with inventory models to aid in achieving effective inventory management. Additionally, advancements in technology have assisted with inventory management among firms that chose to adopt automation in their inventory control practices. Determining inventory turns by calculating ITR is widely accepted as an adequate measure of inventory performance. Arguably, effective inventory management results in greater financial performance.

\section{Literature Review}

\subsection{Institutional Theory and Isomorphism}

Institutional theory of organizations is fundamental to the understanding of organizational behavior. It provides and explanation of how organizations respond to external pressures in ways that encourage the appearance of uniformity across industries (Chandler and Hwang, 2015). Institutional theory highlights the influence of the external environment on organizations, as well as the development of an organization's formal structure and the practices and procedures implemented. In a bid to be considered legitimate, organizations adopt and incorporate several practices, including policies and social norms that have developed and become institutionalized within the external environment. For these reasons, many similarities may exist within organizations, particularly those within the same industries. DiMaggio and Powell (1983) argued that there is no longer a need for improved efficiency or a drive for competitive advantage that initiates changes within an organization because of processes driven by powerful forces that lead organizations to become like each another. In contrast, Kauppi (2013) maintained that, from the standpoint of economic isomorphism, there is a need for efficiency that leads organizations to mimic successful practices in other organizations, rather than a social desire for legitimacy. The theory that best captures the homogeneity enabled by institutional theory is isomorphism. Institutional isomorphic change occurs through "coercive isomorphism that stems from political influence and the problem of legitimacy; mimetic isomorphism resulting from standard responses to uncertainty; and normative isomorphism, associated with professionalization" (DiMaggio and Powell, 1983, p. 150). The most common principle is mimetic isomorphism where organizations meaningfully adopt the practices and model the business structure of an organization that is regarded as a leader in its industry (DiMaggio and Powell, 1983). This mimicking behavior is further described by Kauppi (2013) through frequency-based, outcome-based, and trait-based imitation of one organization by another.

It has been theorized that weaker firms are more vulnerable to influence from the external environment. Zucker (1987) argued that the power of an organization influences its level of compliance, and the extent to which an organization maintains control over its own boundaries determines the level of environmental penetration in its core business activities. This distinction is often created between private and public entities. Public entities which are heavily influenced by state laws are more conforming to external pressures and are subjected to coercive isomorphism. Isomorphism is greater for organizations that interact heavily with different state agencies that will routinely designate industry standards requiring adoption by all organizations (DiMaggio and Powell, 1983).

In the global economy, innovativeness and competitive advantage through differentiation is an encouraged business practice. If this perspective is widely supported, then it is likely that contemporary organizations may have more differences than similarities. This questions the relevance of institutional theory and mimetic isomorphism within today's business environment. Nevertheless, there is soundness to the idea of mimetic organizational behavior due to the uncertainty that organizations face both internally and externally. Uncertainty has been identified as the key factor in isomorphism and the reason why organizations imitate seemingly more developed and more successful organizations. According to institutional theorists, greater ambiguity leads to higher rates of isomorphism (Kauppi, 2013). DiMaggio and Powell (1983, p. 151) supported the idea that "uncertainty is a powerful force that encourages imitation." Uncertainties that organizations are likely to face include risks or environmental factors, as well as uncertainty during the developmental phase in knowing the best strategies and procedures to implement. Similar uncertainties face organizations within the same industries, which encourages mimicking behavior as they imitate the responses of other organizations to these uncertainties. When key technologies are misunderstood or when the goals are undefined, organizations are likely to model themselves after other firms seen as more successful with mimetic isomorphism (DiMaggio and Powell, 1983). Kauppi (2013) argued that isomorphism and imitative behavior may be beneficial to late adopters mainly in relation to technological innovations. He added that organizations can benefit by waiting to see how successful the implementation of a new technology is in an organization, and can also learn from the challenges the organization may have experienced with the technology. Within the Jamaican business environment, there are companies that are considered leaders in their field. Undoubtedly, other organizations mimic the practices and implement the technologies used within these companies. 


\subsubsection{Strategies to Address Institutional Pressures}

Institutional arrangements are not likely to satisfy the interest of all organizations, especially those considered less powerful (Seo and Creed, 2002). Arguably, the best defence to the challenges of institutional pressure is to filter its impact on the development of business strategies, particularly when the interests of the organization are somewhat different from those of the wider business environment. Organizations that strive to be innovative are those that are likely to resist environmental pressures. Therefore, creating strategies to address the influence of the institutional environment should be a primary objective for an innovative organization. Oliver (1991) presented a comprehensive analysis of responsive strategies to institutional pressures. The five strategic responses presented are: "acquiescence, compromise, avoidance, defiance, and manipulation" (Oliver, 1991, p. 151). Oliver (1991) believed that organizations commonly adhere to institutional processes and their acquiescence may take other forms including "habit, imitation, and compliance" (p. 151). The two extremes are "acquiescence", which is a passive approach widely discussed as the common response by organizations, and "manipulation", which is considered the most active response strategy since it seeks change or exerts power over institutional values. An organization's strategic response to institutional pressure will be based on the extent to which the firm's objectives are in line with the standards or ideas that the institutional constituents are seeking to accomplish in pressuring the organization to be more socially and economically accepting (Oliver, 1991).

\subsection{Inventory Management Practices}

Research examining the existence of inventory management practices has indicated that preconceived ideas of inventory control practices has been used to evaluate firms, based on whether they conform to "regular" inventory control strategies such as Vendor Managed Inventory (VMI), Enterprise Resource Planning (ERP), Just-in-time (JIT), and economic order quantity (EOQ). Narayanapillai (2010) assessed the firms within his study based on a classification of IM practices into conventional/traditional and modern. Modern practices were those that utilized EOQ and VMI. It was concluded that firms that implemented modern practices achieved higher ITRs (p. 420). Farooquie and Khan (2010) agreed that modern inventory practices such as JIT and Lean Procurement provide cost savings and improved profitability compared to basic inventory models, and further stated that that traditional inventory methods may fail to ensure desired service levels. Strategy development, including strategies for inventory management, will be ineffective using a "one-size fits all" approach. Firms can tailor practices according to their objectives. Lack of VMI or ERP does not render these strategies ineffective if the objectives of having the right amount of inventory, avoiding excess stock, and stock-outs are achieved.

For SMEs within the retailing and manufacturing/distribution industries in Jamaica, inventory consists of raw materials, work-in-progress, and finished goods. Their inventory control strategies are critical in keeping the inventory at an optimum level to ensure stability of sales in order to gain and maintain profitability. Irrefutably, for these companies their inventory is the backbone of the business; nothing runs without these key materials, neither production nor sales. These companies have numerous stock-keeping units (SKUs) and their inventory control strategies include balancing each inventory based on the type, i.e., raw materials, work-in-progress, or finished goods, and then by categories based on elements such as annual dollar usage and supply chain factors. For this purpose, inventory classification is utilized. The widely-accepted method is ABC classification, where A items are very important to the business, B items are moderately important, and $\mathrm{C}$ items are unimportant (Hatefi, Torabi, and Bagheri, 2014). Hatefi et al., (2014) aptly stated that inventory for many companies includes many items, while the required resources to manage them are often limited. By classifying inventory, firms can focus their limited resources on the most important items. Flores, Olson, and Dorai (1992) also recommended the use of $\mathrm{ABC}$ classification of inventory, but suggested that other factors besides annual dollar usage should be used to classify inventory and should be guided by the nature and type of business. They proposed using lead times, obsolescence, and criticality above financial concerns to rank inventory A, B, or C in order of importance. This shows that there can be variations to common inventory control practices which are tailored to the business objectives, while still achieving the general principle of successful inventory control. Buxey (2006) emphasized that many organizations stock thousands of SKUs, and should create and implement control systems in preparation of the magnitude of the tasks for inventory control, and must further recognize the importance of $\mathrm{ABC}$ classification because all items should not be treated equally. Together with $\mathrm{ABC}$ classification, other widely used inventory models include EOQ, Forecasting, and JIT. For this study, only EOQ will be discussed in depth. Lopez et al., (2013) considered EOQ as the most critical model of inventory management. The concept of establishing a point where an order should be placed (reorder point) and the minimum quantity to be ordered traces beyond the creation of the term Economic Order Quantity (Piasecki, 2001). According to Piasecki (2013), early inventory managers understood the value of knowing at what point inventory should be replenished and the 
amount to be ordered.

\subsubsection{Factors that Influence the Adoption of Inventory Management Practices}

Except for Shah and Shin (2007) who examined how practices differ between retail, manufacturing, and wholesale sectors, few articles have sought to investigate consistencies or differences between inventory management practices among a group of SMEs. Shah and Shin studied the trends and contrasting patterns of inventory practices and performance across different sectors. They found that differences do exist and impact on performance within certain periods. Additionally, they concurred that the impact of IT investment on inventory performance differs across industries. Prakash (2002) provided an explanation of institutional theory and indicated that firms may choose to adopt strategies due to normative reasons and pressures from their environment. Their policies and practices often reflect external pressures, including regulations, as well as public pressure for legitimacy and social acceptance. Chandler and Hwang (2015) stated that institutional theory is essential to the understanding of actions by firms and provides an explanation of how they respond to external pressures by implementing practices that have become institutionalized. This research seeks to expand on these findings by examining whether different or similar strategies exist between retail and manufacturing/distribution SMEs in Jamaica. It will investigate whether similar approaches are influenced by institutional theory, where the policies and governing systems that deliver meaning and solidity to a sector can powerfully affect the development of certain practices in a firm (Sherer, Meyerhoefer, and Peng, 2016).

\subsubsection{Value of Inventory Management}

Inventory management enhances business procedures through effective movement of goods and services, adding to productivity, competitive advantage, service optimization, and market diversification (Chalotra, 2013). By engaging in integrated inventory management practices, SMEs can acquire competitive advantage, survive in a competitive environment, minimize inventory costs while avoiding the consequences of stock-outs, and achieve high ITRs (Narayanapillai, 2010). The reverse is also true as challenges in inventory management will have a harmful effect on firm performance (Farooquie and Khan, 2010). Though SMEs have recognized the importance of inventory management practices, the extent to which inventory control is being integrated as a strategic tool for enhancing performance has been differentiated. Chalotra (2013) found that small scale industries recognize inventory management as an important tool to improve asset productivity and achieve high inventory turns, while helping to target customers and enhance business networks. In addition to usefulness as a supply chain risk mitigation strategy, SMEs acknowledge that the utilization of appropriate inventory control strategies results in enhanced competitive advantage (Chalotra, 2013). In his study of SMEs in India, Narayanapillai (2010) found that, although SMEs understood the value of inventory management, some failed to implement IM practices. While these SMEs saw inventory management as important, they were unclear of its role and how it would deliver immediate financial benefits, resulting in no implementation of inventory control strategies (Narayanapillai, 2010). Research by Narayanapillai also revealed that a significant number of SMEs that pursued IM practices implemented a single method, while those that pursued multiple inventory management practices did so in a heuristic manner. Similarly, Farooquie and Khan's (2010) study of SMEs within the Indian lock industry established that firms were either uninformed about essential techniques to inventory management or were aware, but failed to practice them. They found that inventory management techniques such as JIT or Lean procurement were rarely practiced because firms adopted more practice-based estimations (p. 317). With a focus on EOQ, Piasecki (2001) argued that, even with advancements in technology, companies still fail to implement fundamental inventory models, due in part to the poor results received, which are based on inaccuracies in data inputs. This suggests that knowledge of inventory management will not always translate into practice. Additionally, methods of inventory management within SMEs may be unsystematic and informal, and not integrated as strategy.

\subsubsection{Measuring Inventory Management through ITR}

Research on the impact of inventory management practices on business performance has uncovered an enormous amount of literature, though inconclusive. Throughout the articles reviewed, the determinants of an effective inventory management are ITR. "Inventory turnover ratio (ITR) is a measure of how effectively inventory is being managed" (Narayanapillai, 2010, p. 407). ITR indicates how often a firm's inventory is depleted and replaced over time. ITRs hold great importance in performance analysis (Choudhary and Tripathi, 2012). A low ITR implies poor sales, excess inventory, or overstock, and a higher ITR generally implies a more efficient use of inventory (Farooquie and Khan, 2010). It is necessary to measure a firm's level of inventory because high inventory increases cost and other liabilities for the firm. Within an organization, inventory is considered as both an asset and a liability. Inventory balance remains a challenge for many organizations. Having the right inventory 
is the key objective for inventory management. This position impacts greatly on the firm's competitive advantage and overall performance. Narayanapillai (2010) found that the SMEs that adopted IM practices achieved higher inventory turnover ratios, were more effective in their inventory management, and were more likely to remain competitive in a global environment.

Choudhary and Tripathi (2012) noted that other factors besides inventory, such as marketing strategies, determine the financial performance of firms. Piasecki (2001) discouraged the use of inventory turns to measure performance, since aggressive goals to increase inventory turns may reduce the company's bottom-line due to increases in operational costs. Given the contradictory results and conclusions on the impact of inventory management on financial performance from the literature reviewed, this research intended to show the extent to which inventory management impacts on the financial performance of Jamaican SMEs within the retail and manufacturing/distribution sector. The research also investigated the use of ITR as an accepted means of evaluating IM performance in Jamaican SMEs.

\subsection{Information Technology in Inventory Management}

Experts in the field of inventory management will argue that information technology (IT) through automated systems adds significant value and efficiency to inventory management processes. An automated system helps to optimize inventory by providing current data (Choudhary and Tripathi, 2012). Chen, Pang, and Pan (2014) supported the use of technologies such as Radio Frequency Identification (RFID) which will allow retailers to accurately track inventory movement and make decisions to better align their inventory based on demand and supply. Issues in inventory management related to lack of appropriate methods and under-use of IT will impact negatively on firm performance due to the relationship between inventory performance and business performance (Farooquie and Khan, 2010). However, there are arguments that the investments of IT in inventory management, particularly for small operations, are not worth the returns. These inconsistencies have motivated this research into assessing whether firms that employ manual inventory systems fail at achieving effective inventory management and subsequent financial gains from inventory optimization. Within the context of Jamaican SMEs, this research intended to bring to closure the two paradoxes of the relationship between large investments in IT for inventory management and firm performance. Similar contradictions have been explored in the literature by Shah and Shin (2007). While some may argue that IT impact is incidental through intermediate operational performance related to inventory turnover, others argue that IT investments in inventory management will not lead higher performance and do not provide competitive advantage for the organization.

\section{Research Methodology}

\subsection{Research Methods and Design}

A qualitative methodology was selected as most appropriate for this study. With a qualitative methodology, insight about the different strategies that may vary among different firms can be gained, as well as an understanding of how inventory control methods impacted on the firms' performance. A methods triangulation approach was employed to offer a variety of data collection techniques. The combination used included case studies, questionnaires, non-participant observation, and interviews. The research also included secondary data collection and a review of legislation that may impact the policies implemented by Jamaican SMEs in relation to inventory management.

\subsection{Participants}

The study was confined to SMEs within the retail and manufacturing/distribution industry of the Jamaican economy. The sampling unit for this research consisted of twelve SMEs which included two case studies that employ a maximum of 250 employees. The case study method involved two SMEs to be studied: a distribution company for manufactured foods products (Company A), and a retailer of household appliances and electronics (Company B). A wide study was conducted within these two firms to gather data on their strategies for inventory control. For the two SMEs, a complete and detailed assessment was done on their inventory management system. During the visits, self-administered questionnaires were completed by six participants, along with two structured interviews and observation of various inventory related activities, which included stock counts, and receiving and dispatching of products. Within the ten SMEs of the sampling unit, which included four manufacturing/distribution companies and six retailers, questionnaires were administered to a minimum of four employees whose job functions were directly related to inventory management within the business. Additionally, a structured interview was conducted with an inventory manager and supervisors, and inventory control activities such as stock counts were observed.

The participants who completed the questionnaires were precisely selected based on their job functions and years 
employed in the company. Employees with less than two years of employment were not selected. Employees who were involved in stock management, inventory counts, goods receipt, as well as picking and dispatching of inventory, were selected as the most suitable for the data being collected. Participants selected for interview were of a supervisory and management level. These participants were selected based on their capacity to provide the information required, such as inventory turns and development of company strategies with which participants below such a level may not have been familiar. The sampling method used was a non-random purposive sampling technique. This technique was considered the most appropriate because it allowed the researcher to select the sample that would provide the best information to satisfy the research objectives (White, 2000).

\subsection{Materials/Instruments}

The two instruments used were questionnaires and interviews. Both the questionnaires and interviews were structured to gather information about inventory control strategies, inventory turns, use of automated systems, and factors that influenced the adoption of the implemented inventory management system. The questions for both the interviews and the questionnaires were developed specifically for this research and reviewed by a reputable market research company that has conducted questionnaire-based surveys locally. Questions were subsequently modified based on the advice received from this entity. Additionally, a 'cognitive interviewing' approach was used, where the interview and questionnaires were tested among a group of individuals to identify whether the questions were interpreted correctly (Garcia, 2011).

The questionnaire was developed with 20 closed-ended questions with multiple choice options. It was structured to collect information on current inventory management systems within the SMEs and an evaluation of their performance. For the interview, 17 open-ended questions were prepared to collect the knowledge and experience on the inventory management procedures and performance within the company.

\subsection{Data Collection, Processing, and Analysis}

The data collection process commenced with collection of secondary data, which included reviewing literature on inventory management processes and performance, and the institutional theory of organizational behavior, in addition to a review of Jamaican SMEs and legislation that impacts their business decisions specific to inventory management and control. Primary data was collected throughout twelve SMEs to identify their strategies of inventory control and assess the factors that influenced the development of their inventory management strategies. The data collection within the case studies was extensive as six visits were made to the case study firms. Visits were made to Company A's distribution centre which was operated by a third-party logistics provider (3PL). The first and second visits involved the observation of the dispatching of goods and the receiving of new items into inventory. On the third visit, a stock count exercise was observed. During the third to fourth visits, questionnaires were administered to the six employees whose positions included Inventory Clerks responsible for receiving and dispatching of goods, and Inventory Porters responsible for picking of orders. Two structured interviews were conducted with the Inventory Manager employed by the 3PL and the Inventory Manager employed by Company A. The in-depth interview was conducted with the Inventory Supervisor employed by Company A for over ten years. This decision was taken because, unlike the Inventory Manager who was based at the head office of Company A, the supervisor was based at the distribution centre and was more integrated with the daily activities of the inventory system. Data collected within Company B were just as thorough. However, as a retailer, of the six visits made, three were to the warehouse, one visit was made to each to two retail stores, and one to the head office. All observation was done at the warehouse. The observations included dispatching and receiving of inventory and a stock count exercise. At the warehouse, three questionnaires were administered to the Inventory Supervisor, Inventory Clerk, and Inventory Porter. During the visits to the two retail stores, the Inventory Clerk and Sales Associate completed questionnaires and an interview was conducted with the Retail Store Manager. During the final visit, the in-depth interview was conducted with a Senior Product Manager of Company B.

The data collection process was of a similar design throughout the ten SMEs which included four manufacturing/distribution companies and six retailers. Questionnaires were administered to a minimum of four employees within each SME whose job functions were directly related to inventory management. Additionally, a structured interview was conducted with the Inventory Manager or Supervisor. For observation visits to the SMEs, details of inventory management practices were recorded using the diary method. Data collection and processing were done simultaneously. This commenced with a careful review of the completed questionnaires, notes from the observation, and interview answers, and then categories were created based on research objectives and theories. 


\section{Results}

\subsection{Research Outcome}

The findings of the survey can be summarized in terms of the control strategies being applied to inventory management among the Jamaican SMEs, the use of automated or manual IM systems, challenges and risks being experienced within inventory management, the effectiveness of the control strategies and its impact on business performance, the factors that impacted the implementation of certain inventory management strategies, and the similarities or differences that exist in inventory management among these firms.

\subsubsection{Inventory Control Strategies among the SMEs}

The survey revealed that one or more of the "best practices" of inventory management, such as stock counts, forecasting, EOQ, quality inspections, and inventory classification, are being practiced by the surveyed SMEs. It was found that all the SMEs conduct stock count exercises, also referred to as a periodical review of inventory, though the frequency of the stock count varied. The chart in Figure 1 indicates the frequency of the stock count among the twelve SMEs.

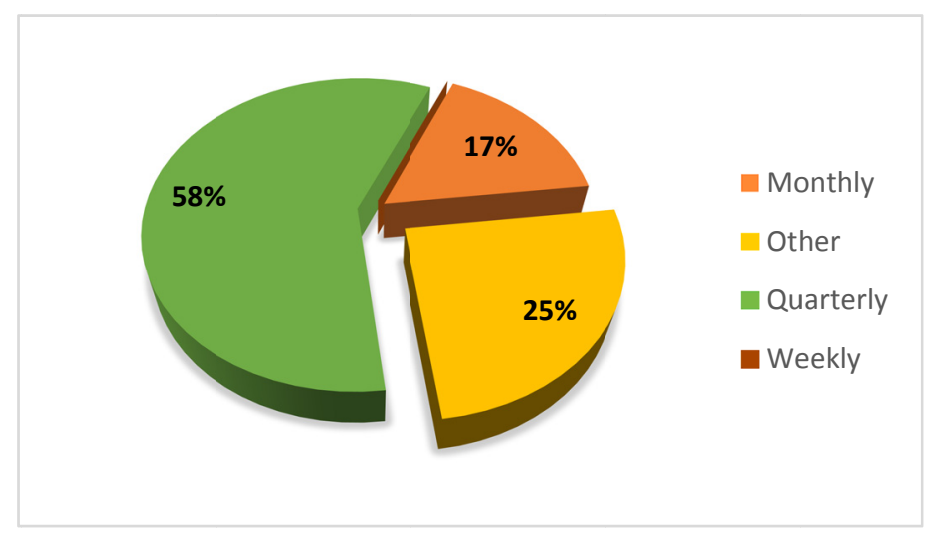

Figure 1. Frequency of stock count exercises

Among the twelve SMEs surveyed, all of them used at least one inventory control strategy. The chart in Figure 2 highlights the number of SMEs that practiced each inventory control strategy. As illustrated, all SMEs conduct stock counts and quality inspections, though only six SMEs practiced classification of inventory and only eight engaged in structured inventory movement.

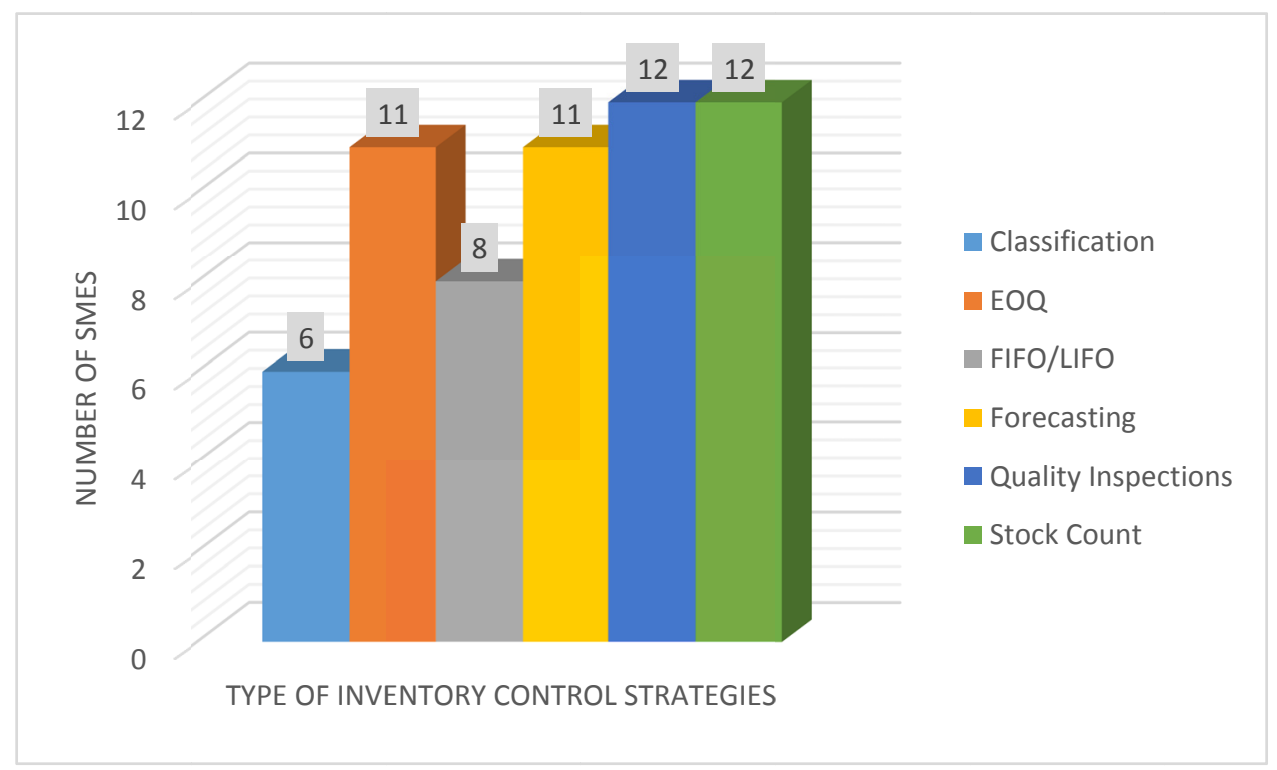

Figure 2. Inventory control strategies by SMEs

The respondents within the SMEs were asked to identify the objectives of the strategies being used. The 
responses are illustrated in Table 1.

Table 1. The purpose of inventory control strategies in the SMEs

\begin{tabular}{ll}
\hline Purpose of inventory strategies & \% of Responses \\
\hline To monitor level of inventory & $40 \%$ \\
To determine what levels of stock should be maintained & $23 \%$ \\
To determine when stock should be reordered & $20 \%$ \\
To determine what quantities should be ordered & $18 \%$ \\
\hline
\end{tabular}

\subsubsection{Factors that Influence Adoption of Inventory Control Strategies}

The survey revealed that the factors that influenced the adoption of the control strategies used by the SMEs are costs, government regulations, success in similar companies, customer expectations, business mandates, number of SKUs, and the type of inventory, i.e., product characteristics and size. The responses are further summarized in the Table 2.

Table 2. Factors that influence inventory control strategies

\begin{tabular}{ll}
\hline Factors that influence adoption & \% of Reponses \\
\hline Cost & $39 \%$ \\
Government regulations & $19 \%$ \\
Type of inventory & $6 \%$ \\
Success in other companies & $22 \%$ \\
Business mandates & $8 \%$ \\
Other & $6 \%$ \\
\hline
\end{tabular}

\subsubsection{Automation in Inventory Management among the SMEs}

The survey revealed that all companies employed a combination of both automated and manual techniques for inventory management, with some being more manual than others. Of the twelve companies surveyed, none were identified as having a fully automated inventory management system. The twelve SMEs surveyed can be classified as having a semi-automated inventory management system with the use of "off-the-shelf" ERP systems such as SAP, QuickBooks Enterprises, ACCPAC, Microsoft Dynamics, Macola Progression, and Peachtree. The SMEs are considered semi-automated because, even with automation implemented in their inventory management practices, manual processes are still being used. All the SMEs were also observed as having manual methods in their stock count exercises. The stock count exercises involve printing inventory details with product codes from the system, counting items, recording the counted quantities, data entry in the inventory system, documenting inaccuracies, and correcting inventory quantities where necessary. An even more manual process observed in three SMEs involved writing the inventory product codes and counted quantities on paper during the stock count. While acknowledging that their IM system is not as fully automated as they wanted, the SMEs commented that the use of automation provides visibility on total inventory and increases efficiency in inventory management.

\subsubsection{Effectiveness of Inventory Control Strategies}

All SMEs surveyed clearly stated that the objectives of their inventory control strategies are to maintain the requisite inventory to satisfy customers' needs and meet business objectives. Respondents were asked to evaluate the performance of their inventory control strategies based on these objectives: $53 \%$ of respondents felt that their inventory management was good, $29 \%$ indicated that it was very good, and $18 \%$ thought that it was fair. There were no respondents who felt that their inventory control systems were poor or very poor in meeting the inventory management objectives. For satisfying customer needs and filling order quantities accurately, $47 \%$ of respondents indicated that they were able to meet customer requests $51-75 \%$ of the time, while $53 \%$ of respondents indicated that they were able to fill customers' requested quantities based on the availability of stock $76-100 \%$ of the time. When asked if customers' orders were filled timely, $24 \%$ of respondents confirmed that they were filled within the requested time $51-75 \%$ of the time, and $76 \%$ confirmed that customers' order were 
filled within the requested time $76-100 \%$ of the time. Stock-outs and inventory accuracy are adequate indications of inefficiencies within inventory control. Both are among the factors used to evaluate the effectiveness of the strategies being used by the SMEs surveyed. From the responses gathered, $41 \%$ indicated that stock-outs occur since inventory items are sometimes out of stock, while 59\% indicated that stock-outs are rare as most inventory items are always in stock. No respondent stated that stock-outs are frequent within their company. When asked to rate the accuracy of their inventory, $35 \%$ stated that it was very accurate, $65 \%$ indicated that it was sometimes accurate, while no respondents indicated that their inventory was mostly inaccurate.

\subsubsection{Challenges and Risks in Inventory Management}

The respondents were asked to identify the challenges and risks that their inventory management faces. Thirty-three percent (33\%) stated that stock-outs were a challenge. All responses are outlined in Table 3.

Table 3. Inventory challenges among the SMEs

\begin{tabular}{ll}
\hline Inventory challenges & \% of Responses \\
\hline Stock-outs & $33 \%$ \\
Inventory inaccuracies & $21 \%$ \\
Excess stock & $12 \%$ \\
Obsolete inventory & $21 \%$ \\
Inventory loss (damages) & $2 \%$ \\
Other & $11 \%$ \\
\hline
\end{tabular}

When asked during the interview sessions how the company intends to mitigate against inventory challenges, the responses were: rationalizing and culling some inventory items, reorganizing warehouse space to increase efficiencies, closer monitoring of key inventory items, upgrading of current inventory management system, and implementing appropriate inventory strategies.

\subsubsection{Similarities and Differences between Practices among the SMEs}

From the survey conducted among the SMEs, the similarities lie in the inventory control strategies used which include stock count, forecasting, and EOQ. Government regulations also impact the SMEs in largely the same way. All the SMEs were found to be only semi-automated with the use of "off-the-shelf" ERPS, while using manual practices to address the challenges of their inventory control. These challenges, which were largely faced by all the SMEs, are stock-outs, inaccuracies, and excess stock. Though the SMEs implemented similar practices, the differences were the frequency of the stock counts, whether monthly or quarterly, as well as the classification of inventory, which was done either by type, value, or sales frequency, and in some cases a combination of all.

\section{Analysis of Data}

\subsection{Analysis of Inventory Strategies}

Prior to research within the Indian machine tool industry, Narayanapillai (2010) believed that application of inventory management practices may not be significantly present in SMEs. However, Narayanapillai found that the level of awareness of the importance and the need for inventory management practices was significantly high among the machine tool SMEs of Bangalore, as $75 \%$ of the SMEs performed one or multiple inventory management practices, depending on their product categories, process characteristics, and customer requirements. In the same way, the present survey revealed that Jamaican SMEs recognized inventory management as a vital tool for effective business performance and were cognizant of the strategies necessary to ensure accuracy and availability of stock. Among the SMEs, there were many similarities in both the inventory control strategies used and the factors that impact the implementation of such strategies. The two case study SMEs were revealed to be more developed in inventory management than the other SMEs within the study. This was expected since both are leaders in their respective industries. All the SMEs surveyed performed a combination of "best practices" for inventory control. These included stock counts, forecasting, establishing EOQs, classification of inventory, and holding safety stock. It is reasonable to assume that the SMEs with similar businesses have the same inventory control practices. However, the survey revealed that the SMEs in different industries also apply similar practices. This supports the theory that the "best practices" in inventory management are applicable across all business types. Achieving a high degree of efficiency in the control of stock in all organizations requires adopting inventory control techniques, such as economic order points, classification of inventory (ABC analysis), and 
safety stock levels (Onwubolu and Dube, 2006), and organizations are encouraged to tailor these strategies to their businesses where necessary. This was evident in the different methods used to classify inventory within six SMEs assessed. Though ABC analysis was not used in all cases, there was separation of inventory items, with different strategies being used to manage each inventory category. It was also found that while each SME conducted stock count exercises, the frequency of the exercise was based on the company's requirements, highlighting the application of strategies based on business needs.

The common features found in the inventory control strategies used are attributed to the fact that all the SMEs examined operate in Jamaica, and thus face similar constraints and are governed by the same regulations. This highlights the influence of external factors on the implementation of inventory control strategies in Jamaican SMEs. The SMEs' inventory practices are shaped by regulations of government bodies such as Bureau of Standards, Ministry of Health, and The Ministry of Commerce. In a cross-national comparison of inventory management practices in South Korea, China, Western Europe, and Hungary, Chikan and Whybark (1990) found that the inventory system in companies was influenced by two major groups of factors: market conditions and cultural background. They added that the strategies practiced by these companies reflected the conditions and requirements of the environment from the economic, political, social, and cultural points of view. While recognizing the importance of their inventory to their supply chain performance, Jamaican SMEs implemented control strategies to guide inventory replenishment, as well as to monitor and maintain adequate stock levels. Inventory control is often considered a challenging task as companies try to find the balance between having the right products to meet varying customer demands, while keeping inventory costs at a minimum. Jamaican SMEs faced issues such as stock-outs and excess stock. Interestingly, none of the SMEs surveyed engaged in lean inventory management or used JIT methods. This is largely because of the associated risks, as operating a lean inventory management system runs the risks of having too little inventory. The SMEs instead opted to hold safety or buffer stocks to meet customer needs.

Narayanapillai (2010) found that the practices of the SMEs he surveyed were conducted in a heuristic manner. This research revealed some similarities in this regard, where inventory control strategies were accepted as not being perfect but satisfactory enough to meet requisite goals. This was evident through unstructured movement of inventory within $35 \%$ of the SMEs, as well as the lack of automation in inventory management, regardless of the recognized benefits in its application for efficient inventory management. Furthermore, the value of the classification of inventory was almost non-existent among the SMEs, with only $50 \%$ classifying their inventory. The classification of inventory guides the control practices of inventory management, such as EOQ, forecasting, and safety stock, by identifying which inventory items are more important and require the most attention. Onwubolu and Dube (2006) stated that when ABC analysis is applied to inventory based on usage rate and value, this determines the importance of items and the level of controls placed on the items to improve inventory performance. The six SMEs that practiced classification of inventory considered it necessary to focus their resources on certain key inventory items that were deemed the most profitable for their business.

\subsection{Analysis of Automation in Inventory Management in Jamaican SMEs}

While automation in inventory management existed among the SMEs, it was under-utilized. The SMEs surveyed indicated that the full version of the ERP systems was cost prohibiting, so most opted for an ERP system that was affordable but not fully tailored to their business needs. Narayanapillai (2010) found that companies within his study bought software for inventory management "but were unable to use it because they found it very difficult to adapt in their enterprises" (p. 411). The SMEs were found to be experiencing limitations to their ERP systems. Two SMEs indicated that their ERP system is unable to produce historical data. The company from a case study pointed out that their ERP misrepresents quantities of saleable items because it does not differentiate damaged and unsaleable items. Except for one SME, most noted that "off-the-shelf" ERPs were not completely configured for the companies because doing so increases the expense for an already costly system. Thus, manual processes were used in combination with automation. The SMEs were also found to be bypassing the system generated EOQs of the automated system to use experience-based reorder points. In an interview, one SME indicated that the system-generated numbers were often disregarded and replaced by estimates provided by the Inventory Manager. The value of automation to Jamaican SMEs is questionable considering that the SMEs chose to rely on their own experiences rather than recommendations put forward by their automated IM system. During the survey of SMEs in the lock manufacturing industry, Farooquie and Khan (2010) found that small companies generally rely more on their history and practice-based estimations. Surveying the SMEs who are leaders in their industry and finding that, even within those organizations, the level of automation is substandard is an indication that the SMEs have conceded to limited automation because the heavy investment cost is a deterrent. Lopez et al., (2013) stated that SMEs seem to be characterized by their poor efforts in optimizing the use of their inventory 
management systems and failed to realize the benefits of using the scientific methods built in their ERPs to determine EOQs and to conduct forecasting. Similarly, Piasecki (2001) stated that in an era of high technological advancements, many organizations are still not seizing the advantages of fundamental inventory models.

Essentially, IT or automation in inventory management is used to monitor inventory levels, reduce inaccuracies, reduce inventory holding costs, and improve overall business performance. Shah and Shin (2007) theorized that IT improves dissemination of information and provides real time information that helps organizations to remove the unknowns in their inventory management, as is the case with ERPs. Arguably, investments in IT result in an improvement in inventory performance, which leads to an increase in financial performance. The relationship remains an area of contention, as many researchers debate whether there is a direct effect of IT investment on financial performance. The responses from the SMEs indicated that when IT investments were made, business performance and overall financial performance were improved. Even with a minor use of automation, the companies surveyed noted success in their inventory control strategies and business performance. With limited automation, $82 \%$ of the SMEs evaluated indicated that their inventory management was good and effective in meeting its objectives. With only $33 \%$ of the SMEs experiencing stock-outs and $21 \%$ having inventory inaccuracies, the data support the argument that the inventory control strategies of these SMEs have been moderately effective. Twenty-five percent $(25 \%)$ of the SMEs indicated that their inventory turns were not at the desired levels, which shows that there is scope for improving their inventory performance. If Jamaican SMEs can manage their inventory effectively, then the outcome is high inventory turns and "high inventory turnover brings revenue" (Chalotra, 2013, p. 217). Better management of inventory can be achieved with greater use of automation in the inventory control strategies of Jamaican SMEs. Similarly, in his study, Narayanapillai (2010) identified several issues related to inventory management that had an adverse effect on the enterprise performance which were credited to lack of use of proper inventory models and under-use of IT.

This research sought to identify whether the challenges typical of inventory management among organizations worldwide were also being experienced by Jamaican companies; the survey revealed that this was the case. The main challenges as identified by SMEs were stock-outs, inventory inaccuracy, and obsolete inventory. Stock-outs or "out-of-stocks (OOS) is a universal issue for retailers" (Huang and Zhang, 2016, p. 13). Though safety stock is often used within the Jamaican SMEs to mitigate against out-of-stocks, this method is sometimes ineffective due to fluctuations in demand. Research has found that consumers who encounter OOS are likely to postpone their purchase, switch to a different store, switch to other options, or simply decide not to purchase anymore, thus creating a series of adverse consequences that hurt the firm's profitability and cause difficulties in demand estimation (Huang and Zhang, 2016). Stock-outs for a manufacturing companies lead to delays in the production process, which creates a ripple effect and a subsequent reduction in financial performance. DeHoratius and Raman (2008) stated that inventory accuracy is critical to any organization. Twenty-one percent $(21 \%)$ of the respondents identified inventory inaccuracy as a challenge to their inventory. DeHoratius and Raman indicated that discrepancies between recorded and actual inventory quantities are substantial in retail organizations. Obsolete inventory are items that have become unsaleable and should be discarded, and thus no longer useful to the company. These items can cause huge losses for the business. For the SMEs surveyed, the two factors that rendered their inventory obsolete were advancements in technology and perishability of items. In reviewing the semi-automated processes of the SMEs compared to the inventory challenges, the researcher evaluated whether challenges and risks being faced could be alleviated with higher automation within these SMEs. Automation in inventory management can help to trigger reorder points to reduce stock-outs, with accurate forecasting for better purchase decisions, determine economic order quantities for inventory replenishment, and track items to reduce obsolete inventory. One of the SMEs used its SAP system to track the shelf life of products to mitigate the risks of inventory becoming obsolete. This is appropriate based on arguments by Chen et al., (2014) that higher use of automation is best for SMEs with perishable products. Additionally, they utilized a FIFO inventory movement that allows the company to fully control which inventory units are to be used to meet demand (Chen et al, 2014). Certainly, automation does not eliminate all challenges associated with inventory management, but it is known to reduce the risks of out-of-stocks and obsolete inventory for perishable items. During their study of a retailer, DeHoratius and Raman (2008) found that even with a highly sophisticated technology system, there was a $65 \%$ level of inaccuracy in their inventory records. Some inventory inaccuracies that may occur even with automation are: selling and restocking errors, replenishment errors, database errors, incomplete data synchronization, and theft (DeHoratius and Raman, 2008). With a similar view, Uçkun, Karaesmen and Savaş (2008) stated that the use of IT in the supply chain makes it easier to collect and store data, but the tracking of inventory is still prone to errors. Periodical review of inventory has proved useful in addressing inaccuracy. 


\subsection{Discussion of the Research Questions}

A critical aspect of this research was to identify the strategies that Jamaican retail and manufacturing/distribution SMEs use for inventory control and the factors that influenced their development. The research also sought to determine the extent to which the strategies for inventory control differed among SMEs in Jamaica within the same industry. The strategies identified within the twelve SMEs are monthly or quarterly stock counts, inventory classification, EOQ, quality inspections, FIFO inventory movement, and forecasting. The SMEs were also found to use ERPs systems combined with manual inventory control procedures. The factors contributing to the development of these strategies are costs, government regulations, inventory characteristics, and success of similar strategies in other firms. The similarities in the control strategies used by the SMEs are quite evident for businesses operating within the same industries, as well as those in different industries. The research also revealed that external factors through government regulations impact greatly on the strategies for inventory control that are adopted. The findings of this research support institutional theory and isomorphism of organizational behavior. Institutional theory speaks to the impact of the external environment, which leads organizations to adopt similar practices and procedures. Institutional theory reasons that organizations adopt and incorporate several practices that have become institutionalized within the external environment. According to Kauppi (2013), forces within the environment encourage convergent business practices, thus creating homogeneity among organizations. DiMaggio and Powell (1983) argued that homogenization is more likely when there is centralization of resources. The findings of the research revealed that government bodies dictate which items can be sold by the SMEs and, for some SMEs, how inventory should be stored. Additionally, the SMEs with perishable inventory items must adhere to strict regulations regarding disposal of items that have passed the time deemed fit for consumer use. The SMEs also rely on government agencies for certification of inventory items. This supports the institutional theory arguments of Kauppi that organizations implement business practices because doing so enhances their legitimacy. For institutional theories, normative pressures influence organizations, sometimes arising from external sources such as the state (Zucker, 1987); the outcome is isomorphism of business practices. Isomorphism can be either mimetic, normative, or coercive. The two extremities are mimetic, which is knowingly adopting the successful practices of other companies, and coercive, which is adopting practices or policies due to government regulations. From the responses provided throughout this research, both mimetic isomorphism and coercive isomorphism are present among Jamaican SMEs. Twenty-one percent $(21 \%)$ of respondents admitted to the adoption of inventory control strategies because of successful use in other companies. This style of imitation is described by Kauppi as outcome-based and otherwise referred to as benchmarking. The SMEs were found to be compliant and adhering to the practices of the institutional environment; they can be described as having an acquiescence approach to institutional pressures (Oliver, 1991). The SMEs' approach to institutional pressure can also be described as compromise (Oliver 1991), as the manufacturing SMEs often bargain with the Jamaican government on the impact of certain regulations on their business operations.

The growth of IT investments in inventory management has become an institutionalized practice. Chandler and Hwang (2015) stated that organizations respond to external pressures by adopting practices that have become institutionalized. The SMEs surveyed were found to have adopted automation due to pressures from the environment, but were not using it to its full potential. This created adverse effects as implied by critics of institutional theory such as Seo and Creed (2002), who argued that institutional arrangements conflict with the technical activities and efficiency demands of the organization because they limit the adoption of diverse and customized business solutions. This was evident through the wide use of "off-the-shelf" ERPs by the SMEs surveyed, which were not customized for their businesses and therefore unable to be effectively used for greater efficiency. Another critique of institutional theory is the limiting of change, as organizations are less likely to make modifications to practices and strategies. Eighty-three percent $(83 \%)$ of the SMEs surveyed indicated that they have not made any recent changes to their inventory control strategies. Except for the retailer of technology products that had designed its own ERP system, the other SMEs adopted various inventory control strategies due to success in other companies, as mandated by the Jamaican Government, and due to cost, with few changes made since inception.

The research aimed to identify the effectiveness of the strategies being used in the SMEs based on their ITR. The strategies were found to be effective based on the standards established by the SMEs. Seventy-five percent (75\%) of the SMEs were achieving their desired inventory turns. From the interviews conducted, it was determined that inventory turnover ratios were not considered the main indicators of inventory management performance for the SMEs. Many rely on frequency of stock-outs and ability to meet demand as the main indicators of the performance of their inventory control strategies. The SMEs were also found to use other strategies, such as 
marketing and sales activities, to move excess inventory or slow-moving items, hence distorting true inventory turns. This supports similar findings by Gaur, Fisher, and Raman (2005) who stated that inventory turns in retail services have a high correlation with gross margin and capital intensity, as well as unexpected increases in sales, and should not be used as a performance analysis. Of the SMEs surveyed, 90\% confirmed that marketing and sales activities were equally important as inventory management. The survey revealed that all the SMEs used automation in their inventory controls systems and the benefits included increased efficiency and accuracy of inventory. However, the level of usage and the lack of optimization by way of all the SMEs still using manual practices led to the classification of Jamaican SMEs as being semi-automated. These findings mirror studies by Ruey-Shun, Chia-Ming, Helms, and Wen-Jang (2008) who addressed the lack of utilization and implementation of ERPs in SMEs. They added that SMEs find most related activities for ERP system implementation difficult, due to untrained personnel, a challenging environment, resource constraints, management system limitations, and limited services from ERP vendors. Faced with similar constraints, the SMEs feared full automation because training of staff would be required. From the interviews conducted, it was clear that the SMEs aspired to implement more automation in their inventory control strategies. All the SMEs have identified improvements in business performance when there were advancements in their inventory control strategies.

\section{Conclusion and Recommendations}

\subsection{Recommendation}

It is recommended that the SMEs adopt other strategies such as Vendor Managed Inventory (VMI) and Lean inventory management to improve their inventory management. It is further recommended that $\mathrm{ABC}$ classification of inventory be implemented as a fundamental practice for inventory control so that the SMEs can focus on the highly valued inventory items for better allocation of time, resources, and strategies to effectively manage inventory items based on their importance to the overall business performance. Since the SMEs experienced improvements in inventory management when implementing automation, greater investments in automation may then redound to improved results. The SMEs should assess the feasibility of added investments in automation by weighing costs versus returns. They may find that, even with a higher initial upfront cost, the payback is worth the investment. The SMEs should steer inventory control strategies away from manual practices because they are labour intensive, time consuming, and prone to human errors. Continuous training of inventory staff is also recommended to increase inventory management performance. The SMEs should also increase monitoring of inventory to reduce risks and increase accuracy. The SMEs should focus on inventory turnover ratios as a measure of the performance of the inventory control strategies being utilized. They will find turning their inventory faster minimizes cost and reduces the likelihood of inventory becoming obsolete.

\subsection{Practical Implications}

Firms that can implement the right inventory control strategies to effectively hold the right balance of inventory while keeping related costs at a minimum can benefit from an increase in financial performance. An objective of the research was to highlight the strategies of inventory control and their impact on business performance. Without an investigation into the financial performance, due to expected reluctance from the SMEs, it is difficult to adequately determine whether the strategies being used were indeed successful in achieving higher financial performance. Nonetheless, this research has provided much insight into the level of IT investments in inventory management of Jamaican firms. This information is important given that few articles have examined the types of automation used in Jamaican SMEs for inventory control. The information from this research may be useful to ERP manufacturers to redesign or build systems tailored to Jamaican firms based on the environmental and regulatory constraints. ERP manufacturers should address the limitations that Jamaican SMEs experience and note that reproducing historical data is a 'must have' feature for these SMEs, and thus include this as a default feature in the development of any ERP system.

This research is fitting and adds value to the wider assessment of inventory control strategies in SMEs. An implication of this research comes from a reframing of two issues: the misuse of automation in SMEs, that is available but mostly underutilized, and the incongruities of ITR as an acceptable measurement of inventory management performance. As a final implication, the findings of the study inspire new research into what is indeed the most appropriate measure of effective inventory control for SMEs and how to persuade SMEs to make feasible investments in IT for benefits to be realized over the long run. By way of institutionalism and the mimetic isomorphic behavior among the SMEs, it is likely that with one of two entities making larger investments in automation will create a benchmark that smaller and developing firms will adopt.

\subsection{Scope for Future Research}

Widening of the research scope to include large firms and entities in other industries would be one of the avenues 
for future research. Future studies can also be undertaken about inventory management from the perspectives of wholesalers, retailers, and manufacturers for large scale industries, thus contributing towards a full determination of isomorphism in Jamaica. A more detailed research collection process regarding the use of RFID tags and barcodes by Jamaica SMEs is also needed. Uncertainty during the developmental stages has been identified as a key factor to mimetic isomorphism. To confirm this, a study that is more focused on newly developed companies should be undertaken. One valuable area for future research is a focus on financial performance and comparing it to inventory performance over different periods for a better assessment of the impact of inventory control strategies on financial performance. Similarly, a more detailed assessment before and after an IT investment in inventory management should be done to assess impact of such an investment.

\subsection{Conclusion}

The study provides substantive support for previous findings on inventory control in SMEs, as well as institutional theory and isomorphism for the development of business practices and strategies. The results of the survey offer useful insights about inventory management within Jamaican firms. With an objective to identify the strategies for inventory management and control among Jamaican SMEs, twelve SMEs were selected, including two case studies, to determine whether the inventory control strategies they used are among the generally accepted strategies referred to as "best practices" to inventory management. Through questionnaires, interviews, and observation, it was found that indeed the "best practices" in inventory control were being used by Jamaican SMEs.

Automation in inventory management in Jamaican SMEs is limited. The SMEs settled for ERPs that were affordable but not fully compatible to business needs. Nevertheless, automation without the use of appropriate strategies is not recommended as this constitutes a critical determinant to the success of inventory control in any business. The research found that, with limited automation, the SMEs rated their inventory management as successful, although this was specific to the business as well as the environmental context. This level of automation may prove detrimental in other environments, highlighting the many ways that the external environment impacts on business strategies. The research found that, based on external requirements (i.e. the customers), the strategies were successful with little automation being required. However, the external environment was also impacting on the strategies of inventory control that the SMEs implemented. SMEs are found to utilize more traditional methods of inventory control with limited automation that was often underutilized. The research has further added to the varied views on the necessity of high investments in IT for inventory management versus the returns. From the data collected, the SMEs were found to be substandard in the use of IT, but were overall satisfied with the effectiveness of their inventory control strategies and labelled them as successful. ITR is not widely accepted as the means to measure inventory performance. The SMEs were found to be traditional in evaluating inventory performance through a basic assessment of ability to meet customers' demands based on available stock. Like similar studies, the research revealed that, even with automation, there were still inventory errors and inaccuracies. Another similarity with past research is the mimetic isomorphic behavior of Jamaican SMEs as they imitated successful strategies in other entities. Evidence from the research highlights the influence of the Jamaican government on the implementation of inventory control strategies which validated the arguments of institutional theory.

\section{References}

Buxey, G. (2006). Reconstructing Inventory Management Theory. International Journal of Operations \& Production Management, 26(9), 996-1012. https://doi.org/10.1108/01443570610682607

Chalotra, V. (2013). Inventory Management and Small Firms Growth: An Analytical Study in Supply Chain. Vision (09722629), 17(3), 213-222. https://doi.org/10.1177/0972262913496726

Chandler, D., \& Hwang, H. (2015). Learning from Learning Theory: A Model of Organizational Adoption of Organizational Strategies at the Micro Foundations of Institutional Theory. Journal of Management, 41(4), 1446-1447. https://doi.org/10.1177/0149206315572698

Chen, X., Pang, Z., \& Pan, L. (2014). Coordinating Inventory Control and Pricing Strategies for Perishable Products. Operations Research, 62(2), 284-300. https://doi.org/10.1287/opre.2014.1261

Chikán, A., \& Whybark, D. (1990). Cross-National Comparison of Production-Inventory Management Practices. $\begin{array}{lllll}\text { Engineering Costs \& Production } & \text { Economics, } & 19(1-3), & 149-156 .\end{array}$ https://doi.org/10.1016/0167-188X(90)90037-I

Choudhary, H., \& Tripathi, G. (2012). An Analysis of Inventory Turnover and its Impact on Financial Performance in Indian Organized Retail Industry. Journal of Services Research, 12(1), 43-64. 
DeHoratius, N., \& Raman, A. (2008). Inventory Record Inaccuracy: An Empirical Analysis. Management Science, 54(4), 627-641. https://doi.org/10.1287/mnsc.1070.0789

DiMaggio, P., \& Powell, W. (1983). The Iron Cage Revisited: Institutional Isomorphism and Collective Rationality in Organizational Fields. American Sociological Review, 48(2), 147-160.

European Union (2015). User Guide to the SME Definition. Luxembourg: Publications Office of the European Union.

Farooquie, P., \& Khan, M.N. (2010). Returning to the Roots for Reducing Inventory Costs in SMEs: A Case of Indian Lock Industry. Journal of Enterprising Culture, 18(3), 315-330. https://doi.org/10.1142/S0218495810000562

Flores, B. E., Olson, D. L., \& Dorai, V. K. (1992). Management of Multicriteria Inventory Classification. Mathematical and Computer Modelling, 16(12), 71-82. https://doi.org/10.1016/0895-7177(92)90021-C

García, A.A. (2011). Cognitive Interviews to Test and Refine Questionnaires. Public Health Nursing, 28(5), 444-450. doi:10.1111/j.1525-1446.2010.0093

Gaur, V., Fisher, M., \& Raman, A. (2005). An Econometric Analysis of Inventory Turnover Performance in Retail Services. Management Science, 51(2), 181-194. https://doi.org/10.1287/mnsc.1040.029

Hatefi, S., Torabi, S., \& Bagheri, P. (2014). Multi-criteria ABC inventory classification with mixed quantitative and qualitative criteria. International Journal of Production Research, 52(3), 776-786. http://dx.doi.org/10.1080/00207543.2013.838328

Huang, Y., \& Zhang, Y. (2016). The Out-of-Stock (OOS) Effect on Choice Shares of Available Options. Journal of Retailing, 92(1), 13-24. https://doi.org/10.1016/j.jretai.2015.07.001

Kang, Y., \& Gershwin, S. (2005). Information Inaccuracy in Inventory Systems: Stock Loss and Stockout. IIE Transactions, 37(9), 843-859. doi: 10.1080/07408170590969861

Kauppi, K. (2013). Extending the Use of Institutional Theory in Operations and Supply Chain Management Research Review and Research Suggestions. International Journal of Operations \& Production Management, 33(10), 1318-1345. https://doi.org/10.1108/IJOPM-10-2011-0364

Khader, S., Rekik, Y., Botta-Genoulaz, V., \& Campagne, J. (2014). Inventory Management Subject to Multiplicative Inaccuracies. International Journal of Production Research, 52(17), 5055-5069. http://dx.doi.org/10.1080/00207543.2014.895444

Lopez, J., Mendoza, A., \& Masini, J. (2013). A Classic and Effective Approach to Inventory Management. International Journal of Industrial Engineering-Theory Applications and Practice, 20(5-6), 372-386.

Meyer, J. W., \& Rowan, B. (1997). Institutionalized Organizations: Formal Structure as Myth and Ceremony. American Journal of Sociology, 83(2), 340-363. Retrieved from http://www.jstor.org/stable/2778293

Meyer, R., \& Höllerer, M. (2014). Does Institutional Theory Need Redirecting? Journal of Management Studies, 51 (7), 1221-1233. https://doi.org/10.1111/joms.12089

Narayanapillai, R. (2010). An Evaluation of Inventory Management and Performance in Indian Machine Tool SMEs: An Exploratory Study. International Journal of Innovation \& Technology Management, 7(4), 405-422. https://doi.org/10.1109/ICMIT.2008.4654578

Oliver, C. (1991). Strategic Responses to Institutional Processes. The Academy of Management Review, 16(1), 145-179.

Onwubolu, G., \& Dube, B. (2006). Implementing an Improved Inventory Control System in a Small Company: A Case Study. Production Planning \& Control, $17(1), \quad 67-76$. http://dx.doi.org/10.1080/09537280500366001

Piasecki, D. (2001). Optimizing Economic Order Quantity. IIE Solutions, 33(1), 30-34. Retrieved from http://solutions.iienet.org/

Prakash, A. (2002). Green Marketing, Public Policy and Managerial Strategies. Business Strategy \& The Environment, 11(5), 285-297. https://doi.org/10.1002/bse.338

Ruey-Shun, C., Chia-Ming, S., Helms, M., \& Wen-Jang, J. (2008). Role Negotiation and Interaction: An Exploratory Case Study of the Impact of Management Consultants on ERP System Implementation in SMEs in Taiwan. Information Systems Management, 25(2), 159-173. http://dx.doi.org/10.1080/10580530801941371 
Seo, M., \& Creed, W. E. (2002). Institutional Contradictions, Praxis, and Institutional Change: A Dialectical Perspective. The Academy of Management Review, 27(2), 222-247. Retrieved from http://www.jstor.org/stable/4134353

Shah, R., \& Shin, H. (2007). Relationships among information technology, inventory, and profitability: An investigation of level invariance using sector level data. Journal of Operations Management, 25(4), 768-784. https://doi.org/10.1016/j.jom.2007.01.011

Sherer, S., Meyerhoefer, C., \& Peng, L. (2016). Applying institutional theory to the adoption of electronic health records in the U.S. Information \& Management, 53(5), 570-580. https://doi.org/10.1016/j.im.2016.01.002

Uçkun, C., Karaesmen, F., \& Savaş, S. (2008). Investment in Improved Inventory Accuracy in a Decentralized Supply Chain. International Journal of Production Economics, 113(2), 546-566. https://doi.org/10.1016/j.ijpe.2007.10.012

White, B. (2000). Dissertation Skills. Hampshire: South-Western Cengage Learning.

Zucker, L. G. (1987). Institutional Theories of Organization. Annual Review of Sociology, 13, 443-464. https://doi.org/10.1146/annurev.so.13.080187.002303

\section{Copyrights}

Copyright for this article is retained by the author(s), with first publication rights granted to the journal.

This is an open-access article distributed under the terms and conditions of the Creative Commons Attribution license (http://creativecommons.org/licenses/by/4.0/). 